\title{
Flor Yeast Diversity and Dynamics in Biologically Aged Wines
}

\author{
Vanessa David-Vaizant ${ }^{1,2}$ and Hervé Alexandre ${ }^{1,2 *}$ \\ ${ }^{1}$ AgroSup Dijon, PAM UMR A 02.102, Université Bourgogne Franche-Comté, Dijon, France, ${ }^{2}$ Equipe VAIMiS, Institut \\ Universitaire de la Vigne et du Vin, Dijon, France
}

Wine biological aging is characterized by the development of yeast strains that form a biofilm on the wine surface after alcoholic fermentation. These yeasts, known as flor yeasts, form a velum that protects the wine from oxidation during aging. Thirty-nine velums aged from 1 to 6 years were sampled from "Vin jaune" from two different cellars. We show for the first time that these velums possess various aspects in term of color and surface aspects. Surprisingly, the heterogeneous velums are mostly composed of one species, S. cerevisiae. Scanning electron microscope observations of these velums revealed unprecedented biofilm structures and various yeast morphologies formed by the sole $S$. cerevisiae species. Our results highlight that different strains of Saccharomyces are present in these velums. Unexpectedly, in the same velum, flor yeast strain succession occurred during aging, supporting the assumption that environmental changes are responsible for these shifts. Despite numerous sample wine analyses, very few flor yeasts could be isolated from wine following alcoholic fermentation, suggesting that flor yeast development results from the colonization of yeast present in the aging cellar. We analyzed the FLO11 and ICR1 sequence of different S. cerevisiae strains in order to understand how the same strain of $S$. cerevisiae could form various types of biofilm. Among the strains analyzed, some were heterozygote at the FLO11 locus, while others presented two different alleles of ICR1 (wild type and a 111 bp deletion). We could not find a strong link between strain genotypes and velum characteristics. The same strain in different wines could form a velum having very different characteristics, highlighting a matrix effect.

Keywords: flor yeast, biofilm, wine, Saccharomyces cerevisiae, scanning electron microscopy, FLO11, vin jaune

\section{INTRODUCTION}

Wine is produced through the action of a complex microbial consortium (Petruzzi et al., 2017) composed among others of numerous non-Saccharomyces yeast species and a high diversity of S. cerevisiae (Capece et al., 2016). In the world of S. cerevisiae, flor yeast constitutes an exception. Flor yeast or flor velum yeasts can grow at the surface of different wines. These flor yeasts can be found in very specific wine processes known as biological aging practiced in Spain (Andalusia), Italy (Sardinia), Hungary and France (Jura) to produce Xeres, Vernaccia di Oristano, Szamorodni, and Vin Jaune wines, respectively.

In the classical wine process, yeast dies in the absence of sugar and oxygen at the end of the alcoholic fermentation. However, in the case of biological aging, the common characteristic of these wines is that after alcoholic fermentation, they are transferred into barrels, leaving 
an airspace. According to different authors (Esteve-Zarzoso et al., 2001; Aranda et al., 2002) in these conditions of nitrogen and sugar depletion encountered at the end of alcoholic fermentation, the yeast shifts from a fermentative to an oxidative metabolism favored by the presence of oxygen. Furthermore, at the diauxic shift, an increase in FLO11 expression is observed which leads to an increase in cell surface hydrophobicity, facilitating the aggregation of cells and the entrapment of carbon dioxide, allowing the cell aggregate to rise to the surface and develop a biofilm (Zara et al., 2005). Thus, based on this model, yeasts responsible for alcoholic fermentation could be responsible for forming biofilm. However, to our knowledge, only two studies have compared the yeast Saccharomyces present during alcoholic fermentation to those present in the velum (Esteve-Zarzoso et al., 2001; Naumova et al., 2005). The first study concluded that yeasts responsible for alcoholic fermentation are different from velum yeast. However, the must in this study was inoculated with commercial yeast (Esteve-Zarzoso et al., 2001) which could have influenced the development of indigenous yeast. In the second study, Naumova et al. (2005) demonstrated that among all the S. cerevisiae yeasts isolated at distinct stages of sherry making (young wine, solera, and criadera) in various winemaking regions of Spain, that sherry yeasts diverged from primary winemaking yeasts. Thus, not all Saccharomyces are able to form a biofilm (Alexandre, 2013; Legras et al., 2016). The ability to form a biofilm is closely linked to the specific FLO11 alleles present in flor yeast (Fidalgo et al., 2006). Indeed, the FLO11 promoter is $0.1 \mathrm{~kb}$ shorter and the coding sequence is $1 \mathrm{~kb}$ larger in flor-forming yeast compared to non-flor-forming yeast (Fidalgo et al., 2006; Zara et al., 2009; Legras et al., 2014). These changes reflecting evolutionary adaptations (Fidalgo et al., 2006) result in increased protein glycosylation and hydrophobicity of the Flo11 glycoprotein of flor yeast (Zara et al., 2005; Fidalgo et al., 2006), which allows cells to form a biofilm. Other distinct genetic features characterize $S$. cerevisiae flor yeast, including chromosomal polymorphism and aneuploidy (Bakalinsky and Snow, 1990; Martinez et al., 1995; Ibeas and Jimenez, 1996; Guijo et al., 1997; Legras et al., 2014). All the flor strains share these specificities and can be clustered in the same group that has evolved to adapt to the specific wine surface niche encountered during wine biological aging (Legras et al., 2016).

Recently, genome sequencing and comparative genomic analysis of the three $S$. cerevisiae strains used for the production of sherry-type wines in Russia has been reported (Eldarov et al., 2018). They observed than gene polymorphism not only affect FLO11, but also genes involved in yeast morphology, carbohydrate metabolism, ion homeostasis, response to osmotic stress, lipid metabolism, DNA repair, cell wall biogenesis. Gene polymorphism in sherry strains is mainly due to SNP/InDel accumulation. These authors also report the presence of genes in the flor strain missing in the reference strain such as MPR1 gene coding for $\mathrm{N}$-acetyltransferase that is involved in oxidative stress tolerance via proline metabolism.

Besides these genetic specificities which explain the ability of the yeast to form biofilm, metabolomics and proteomic studies have revealed how these yeasts have adapted physiologically and metabolically to their environment (Moreno-García et al., 2014, 2015, 2017). For example flor yeast are resistant to ethanol and it has recently been shown that ethanol tolerance could partly be due to activation of genes related with the unfolded protein response (UPR) and its transcription factor Haclp (NavarroTapia et al., 2016). The proteomic studies highlighted the overexpression of proteins involved in non-fermentable carbon uptake, glyoxylate and TCA cycle and cellular respiration in flor yeast under biofilm conditions compared to flor yeast grown in synthetic media rich in sugar (Moreno-García et al., 2015). Although the genetic, metabolic and physiological specificities that allow flor yeasts to develop as biofilms have been described and reviewed in-depth (Alexandre, 2013; Legras et al., 2016), knowledge on flor yeast ecology is scarce. The origin of these yeasts is still unknown, raising the question of whether they are present on grapes or found in the cellar? As stated above, there is still no strong evidence that yeasts responsible for alcoholic fermentation are the same as those present in the velum. It has been shown that Brettanomyces bruxellensis is sometimes present with S. cerevisiae (Ibeas et al., 1996); however, this has never been confirmed and it is still unknown whether other species are present in the velum. Charpentier et al. (2009) reported that different $S$. cerevisiae strains could be present in one velum but it is still unknown if this is a general feature. Furthermore, wine aging for Vin Jaune, Xeres, Vernaccia di Oristano and Szamorodni lasts several years (6 years for vin jaune). During these 6 years of aging, many changes can occur in the cellar environment, such as that of the temperature between summer and winter. To our knowledge, no study has yet been performed on these changes in environmental conditions responsible for flor yeast succession and community shift. The aim of the present study was to try to answer these questions.

\section{MATERIALS AND METHODS}

\section{Velum and Strain Isolation Protocol}

All the microorganisms were isolated from French Vin Jaune originated from the Jura region (France) and made from Savagnin grape variety which come from two different wine estate working with indigenous yeasts. The Savagnin wines samples contained depending on the vintage $12.5-13.5 \%(\mathrm{v} / \mathrm{v})$ alcohol, with a $\mathrm{pH}$ ranging from 3.1 to 3.4 , and the acetic acid ranging from 200 to $500 \mathrm{mg} / \mathrm{L}$.

Microorganisms were sampled from wine at the end of alcoholic fermentation, from wine at the beginning of the biological aging process (when the wine is transfer from fermentation tank to barrels for aging), and from velum. Thirtyseven velums were recovered by sliding stainless steel chips under the velum present at the surface of the wine. To isolate yeast and bacteria, serial dilutions were performed with each sample and each dilution was spread either on YPD medium $\left(5 \mathrm{~g} . \mathrm{l}^{-1}\right.$ yeast extract, $10 \mathrm{~g} . \mathrm{l}^{-1}$ peptone, $20 \mathrm{~g} . \mathrm{l}^{-1}$ glucose, and 20 g.l ${ }^{-1}$ agar supplemented with chloramphenicol at $200 \mathrm{ppm}$ to inhibit the development of bacteria) and LAC medium

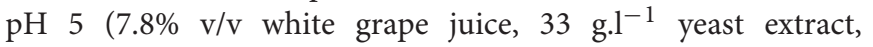


0.6 g. $\mathrm{l}^{-1}$ tween $80,80 \mathrm{mg} . \mathrm{l}^{-1} \mathrm{MnSO}_{4} \mathrm{H}_{2} \mathrm{O}$, and 20 g.l ${ }^{-1}$ agar) supplemented with natacid at $50 \mathrm{ppm}$, respectively. Cultures were incubated for $48 \mathrm{~h}$ and 1 week at $25^{\circ} \mathrm{C}$ for yeast and bacteria respectively.

\section{Biological Aging With Isolated Strains}

Five strains of $S$. cerevisiae isolated from five velums with different morphological characteristics $(14.28 \mathrm{O}, 34.22 \mathrm{O}, 36.2 \mathrm{~J}, 8.1 \mathrm{~J}, 23.1 \mathrm{O})$ were cultivated in $10 \mathrm{ml}$ of YPD broth $\left(36 \mathrm{~h}, 28^{\circ} \mathrm{C}\right)$. Each strain was grown in two different synthetic Fornachon media (Fornachon, 1953) containing either 4 or $10 \%$ (v/v) ethanol and two different French vin jaunes made from Savagnin grapes. Synthetic Fornachon medium was prepared as follows: yeast extract 1 g.l ${ }^{-1},\left(\mathrm{NH}_{4}\right)_{2} \mathrm{SO}_{4} 0.5$ g.l ${ }^{-1}, \mathrm{MgSO}_{4} 1$ g. ${ }^{-1}, \mathrm{CaCl}_{2}$

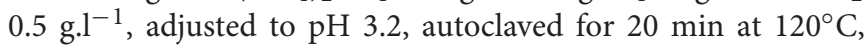
following the addition of $4 \%$ or $10 \%(\mathrm{v} / \mathrm{v})$ ethanol. Each Savagnin wine and synthetic Fornachon medium was inoculated with $10^{6}$ cell. $\mathrm{ml}^{-1}$. Each velum was observed after 1 month. The identity of each strain from each velum was controlled by PCR interdelta analysis as described below.

\section{Scanning Electron Microscopy}

Cells were fixed on stainless steel by a solution of $2.5 \%$ glutaraldehyde in $0.1 \mathrm{M}$ phosphate buffer $\mathrm{pH} 7.2$ for $1 \mathrm{~h}$ at $4^{\circ} \mathrm{C}$. The samples were then washed three times with phosphate buffer for $20 \mathrm{~min}$ at room temperature. Dehydration was performed by successive immersions in solutions of increasing ethanol content $(70,90,100 \%)$, then three times for $10 \mathrm{~min}$ each in successive baths of ethanol-acetone solution (70:30, 50:50, $30: 70,100)$ and air-dried. Afterward, the samples were coated with a thin carbon layer using a CRESSINGTON 308R and observed with a JEOL JSM7600F scanning electron microscope (JEOL, Ltd.). Scanning electron microscopy was performed at $5 \mathrm{kV}$ and the samples were observed at a working distance of $14.9 \mathrm{~mm}$.

\section{Identification of Yeast Isolate}

Genomic DNA of yeast was prepared from yeast cultures on YPD agar after 2 days of incubation with InstaGene Matrix Bio-Rad. First InstaGene Matrix had to be mixed at moderate speed on a magnetic stirrer to maintain the matrix in suspension then briefly pick an isolated yeast colony and suspend it in $30 \mu \mathrm{L}$ of InstaGene Matrix. The suspension was incubated in a thermal cycler at $56^{\circ} \mathrm{C}$ for $50 \mathrm{~min}$, then at $100^{\circ} \mathrm{C}$ for $8 \mathrm{~min}$. Afterward, $30 \mu \mathrm{L}$ DEPC water was added and the suspension centrifuged at $16,250 \times g$ for 3 min. $3 \mu \mathrm{L}$ of the resulting supernatant was used for $30 \mu \mathrm{L}$ PCR reaction. For species identification, the 5.8S-ITS region was amplified by PCR with the primers ITS $15^{\prime}$-TCCGTAGGTGAACCTGCGG-3' and ITS $45^{\prime}$ TCCTCCGCTTATTGATATGC-3'. PCR was performed in $40 \mu \mathrm{l}$ of $1.5 \mathrm{mM} \mathrm{MgCl}_{2}, 0.2 \mathrm{mM}$ dNTPs, $1 \mu \mathrm{M}$ of each primer, $0.025 \mathrm{U}$ of Taq polymerase (Promega Corp., Madison, WI, United States) and 100 ng of yeast DNA. A T100 thermal cycler (Bio-Rad, Hercules, CA, United States) was used with a program described elsewhere (Esteve-Zarzoso et al., 1999). The amplified PCR products were analyzed by capillary electrophoresis on a MultiNA MCE 202 (Shimadzu, France) at $37^{\circ} \mathrm{C}$ for $75 \mathrm{~s}$ using the DNA-1000 kit (Shimadzu, France) containing the separation buffer with SyBer Gold (Invitrogen, France) and an internal size calibrator. They were automatically injected onto chips with a maximum rate voltage of $1.5 \mathrm{kV}$ and a maximum current of $250 \mathrm{~mA}$; the peaks were identified using a LEDexcited (470 $\mathrm{nm}$ excitation wavelength) fluorescence detector. The size of the amplified DNA fragments was calculated on the MultiNA using the (GeneRuler 100 bp Plus DNA Ladder, Thermo Fisher Scientific, Inc., Waltham, MA, United States). Then the PCR products were sequenced with a cycle extension DNA sequencer (Beckman Coulter Cogenics, Essex, United Kingdom). The BLASTN algorithm was applied to the GenBank database for sequence identification ${ }^{1}$. All sequences are available on NCBI under accession numbers.

For S. cerevisiae differentiation, PCR interdelta analysis was performed according to Legras and Karst (2003) using S. cerevisiae DNA extracted as described below. One fresh colony was suspended in a microcentrifuge tube with $200 \mu \mathrm{L}$ buffer (2\% Triton X-100, SDS, $100 \mathrm{mM} \mathrm{NaCl}, 10 \mathrm{mM}$ Tris- $\mathrm{HCl}, \mathrm{pH}$ 8.0, $1 \mathrm{mM} \mathrm{Na} 2$ EDTA). $80 \mu \mathrm{L}$ of chloroform-alcohol isoamylic (25:24:1) and $0.3 \mathrm{~g}$ glass beads (Sigma, Z250465) were added. The suspension was vortexed at the maximum setting for $2 \mathrm{~min}$ and place in ice for $2 \mathrm{~min}$., $200 \mu \mathrm{L}$ Tris-EDTA, pH 8.0, was added mixed to each tube and the suspension was centrifuged for $5 \mathrm{~min}$ at $12,500 \mathrm{rpm}$. The supernatant was transferred to a new microcentrifuge tube and $1 \mathrm{~mL}$ absolute ethanol was added to precipitate the DNA. The pellet was washed with $1 \mathrm{~mL}$ of $70 \%$ ethanol and centrifuged for $3 \mathrm{~min}$ at 12,500 rpm. The DNA pellet was dried at $90^{\circ} \mathrm{C}$ for $5 \mathrm{~min}$ and suspended in $50 \mu \mathrm{L}$ of milliQ water. The DNA concentrations of the samples were then standardized $(100 \mathrm{ng} / \mu \mathrm{l})$ on the basis of optical density at $260 \mathrm{~nm}$, by adding MilliQ water, as appropriate, and the samples were then stored at $4^{\circ} \mathrm{C}$.

\section{Total DNA Extraction}

At least $100 \mu \mathrm{L}$ of velum were centrifuged for $5 \mathrm{~min}$ at $4^{\circ} \mathrm{C}, 12,000$ $\mathrm{rpm}$. The total DNA of pelleted microorganisms was extracted as described by Longin et al. (2016) using CTAB, proteinase $\mathrm{K}$ at $10 \mathrm{mg} / \mathrm{mL}$ and PVPP at $10 \%$. The DNA concentrations of the samples were then standardized $(100 \mathrm{ng} / \mu \mathrm{l})$ on the basis of optical density at $260 \mathrm{~nm}$, by adding DEPC-treated water, as appropriate, and the samples were then stored at $-20^{\circ} \mathrm{C}$.

\section{DGGE Analysis}

The D1 domain of the fungal 26S rRNA gene was amplified with the primers NL1-GC (5'-CGCCCG CCGCGCGCGGCGGGCGGGGCGGGGGCCATATCAATAAG CGGAGGAAAAG-3') and LS2 (5'-ATTCCCAAACAACTC GACTC-3'), as reported in a previous study (Cocolin et al., 2000). The NL1-GC primer had a 39-bp GC-clamp sequence at its $5^{\prime}$ end to prevent the complete denaturation of amplicons. PCR was performed in a reaction volume of $50 \mu \mathrm{l}$, with $1.5 \mathrm{mM}$ $\mathrm{MgCl}_{2}, 0.2 \mathrm{mM}$ dNTPs, $0.2 \mu \mathrm{M}$ of each primer, $2.5 \mathrm{U}$ of Taq polymerase (Promega Corp., Madison, WI, United States) and 10-100 ng of yeast DNA. Reactions were run for 30 cycles of

\footnotetext{
${ }^{1}$ http://www.ncbi.nlm.nih.gov/BLAST/
} 
A

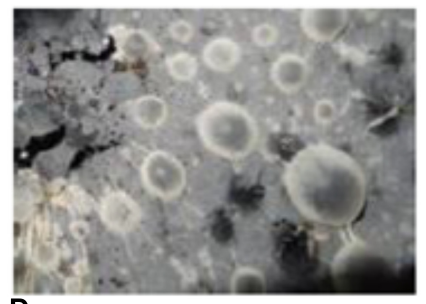

D

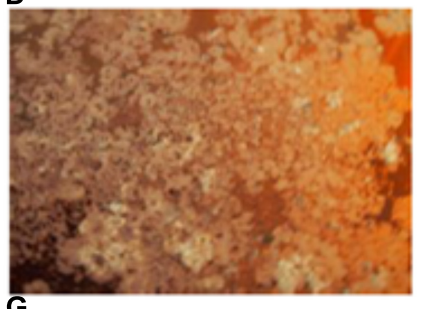

G

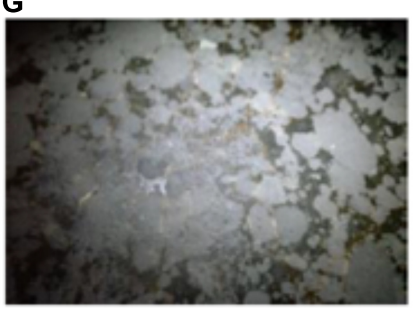

B
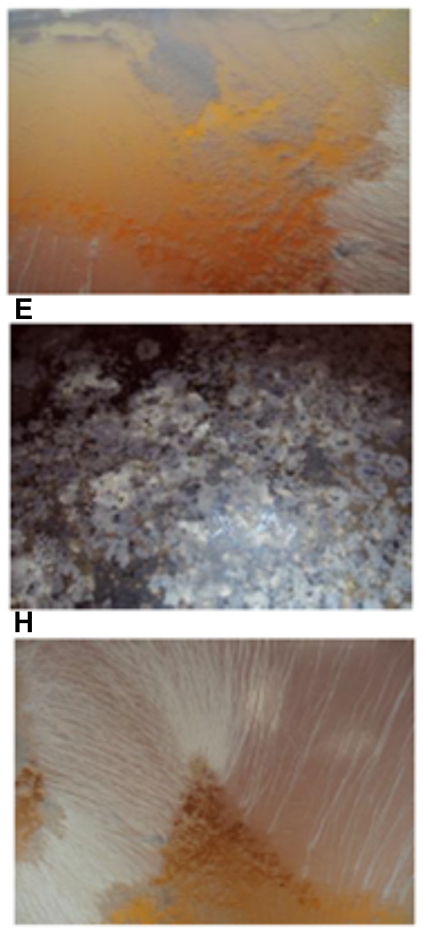

c

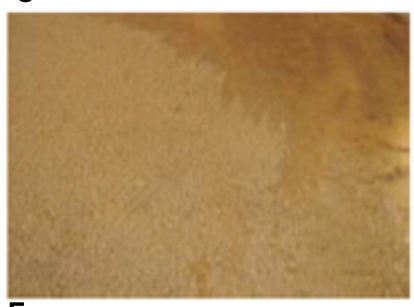

$\mathbf{F}$

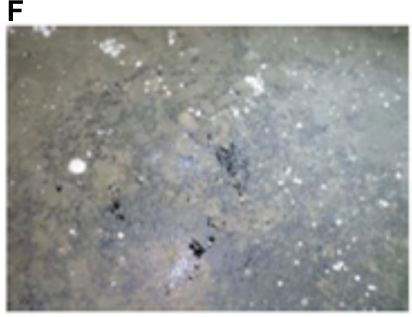

FIGURE 1 | Flor yeast velum characteristic: (A) gray velum with blisters; (B) pink velum with wrinkles; (C) yellow thick and granular velum; (D) mix of white, brown and yellow velum; (E) mix of gray, black, yellow and white velum; (F) gray fine and smoothy velum; (G) black velum with islands; (H) white velum with wrinkles.

denaturation at $95^{\circ} \mathrm{C}$ for $60 \mathrm{~s}$, annealing at $52^{\circ} \mathrm{C}$ for $45 \mathrm{~s}$ and extension at $72^{\circ} \mathrm{C}$ for $60 \mathrm{~s}$. An initial 5 -min denaturation at $95^{\circ} \mathrm{C}$ and a final 7 -min extension at $72^{\circ} \mathrm{C}$ were used. The products (250 bp) were analyzed by capillary electrophoresis on a MultiNA MCE 202 (Shimadzu, France).

Vertical polyacrylamide gels (acrylamide-bis acrylamide 37, 5:1, Bio-Rad, Hercules, CA, United States), with a denaturing gel of $35-50 \%$ polyacrylamide, were used for DGGE. The $100 \%$ chemical denaturing solution consisted of $3.5 \mathrm{M}$ urea (SigmaAldrich) and 20\% (v/v) formamide (Sigma-Aldrich) in $2 \mathrm{~mL}$ TAE $(50 \times)$.

APS (Sigma-Aldrich A3678) and TEMED (Sigma-Aldrich T9281) were added to each gel before being mixed at $4^{\circ} \mathrm{C}$ to create the denaturing gradient. We mixed 40- $\mu$ l samples of PCR amplicons with $10 \mu \mathrm{l}$ of (100\%) glycerol before loading on the gel. A DCode apparatus (Bio-Rad) was used for DGGE in $1 \times \mathrm{TAE}$, at $60^{\circ} \mathrm{C}$ for $5 \mathrm{~h} 30 \mathrm{~min}$, with a constant voltage of $130 \mathrm{~V}$. The gels were stained $10 \mathrm{~min}$ with $10 \times$ BET (SigmaAldrich E1510) in $1 \times$ TAE and the bands were visualized and photographed under UV transillumination. The bands were excised from the gels and the DNA was eluted overnight in $40 \mu \mathrm{l}$ of water MilliQ at $4^{\circ} \mathrm{C}$. The DNA was re-amplified with the same pair of primers without the GC-clamp and sequenced with a cycle extension DNA sequencer (Beckmann Coulter Cogenics, Essex, United Kingdom). The BLASTN algorithm was applied to the GenBank database for sequence identification (see footnote 1). All sequences are available on NCBI under the following accession number from MH276962 to MH276980 and from MH252537 to MH252566.

\section{FL011 Polymorphisms}

The length of FLO11p was measured from the amplification of FLO11 alleles with the primers FLO11 (Flo11IntFw CTCCCTCATCATGTTGTGGTTC), and (Flol1IntRv AACGACGGTGGTTGAGACAA) according to Legras et al. (2014). The PCR reaction was performed with Expand High Fidelity DNA polymerase (Roche) to amplify this long DNA fragment. The PCR program: $94^{\circ} \mathrm{C}$ for $2 \mathrm{~min}$, followed by 10 cycles: $94^{\circ} \mathrm{C}$ for $15 \mathrm{~s}, 61^{\circ} \mathrm{C}$ for $30 \mathrm{~s}, 68^{\circ} \mathrm{C}$ for $5 \mathrm{~min}$ and 20 cycles at $94^{\circ} \mathrm{C}$ for $15 \mathrm{~s}, 61^{\circ} \mathrm{C}$ for $30 \mathrm{~s}$, and $68^{\circ} \mathrm{C}$ for $5 \mathrm{~min}+$ a $5 \mathrm{~s}$ cycle prolongation for each successive cycle. The PCR products were subjected to electrophoresis for $1 \mathrm{~h}$ at $100 \mathrm{~V}$ in $0.7 \%$ agarose gels which were then stained with ethidium bromide $(14 \mathrm{mg} / \mathrm{ml})$ for visualization of the DNA bands under UV light. Fragment sizes were estimated by comparison with DNA size markers (GeneRuler $1 \mathrm{~Kb}$ DNA Ladder, Thermo Fisher Scientific, Inc., Waltham, MA, United States), with Quantity One 4.6.5 software from Bio-Rad.

The FLO11 promoter deletion was performed with the primer pair Flo11promFw CAGCCCCAGAGTATGTTCTCACAG and Flo11promRv AATCACCTTCTAAACGCTCGGA. This PCR was performed with Taq polymerase (Promega Corp., Madison, WI, United States). The PCR program was $95^{\circ} \mathrm{C}$ for $5 \mathrm{~min}$, followed by 30 cycles of $95^{\circ} \mathrm{C}$ for $30 \mathrm{~s}, 56^{\circ} \mathrm{C}$ for $45 \mathrm{~s}$, and 
TABLE 1 | Identification of wine and velum yeast by different molecular techniques (5,8S PCR and 26S DGGE).

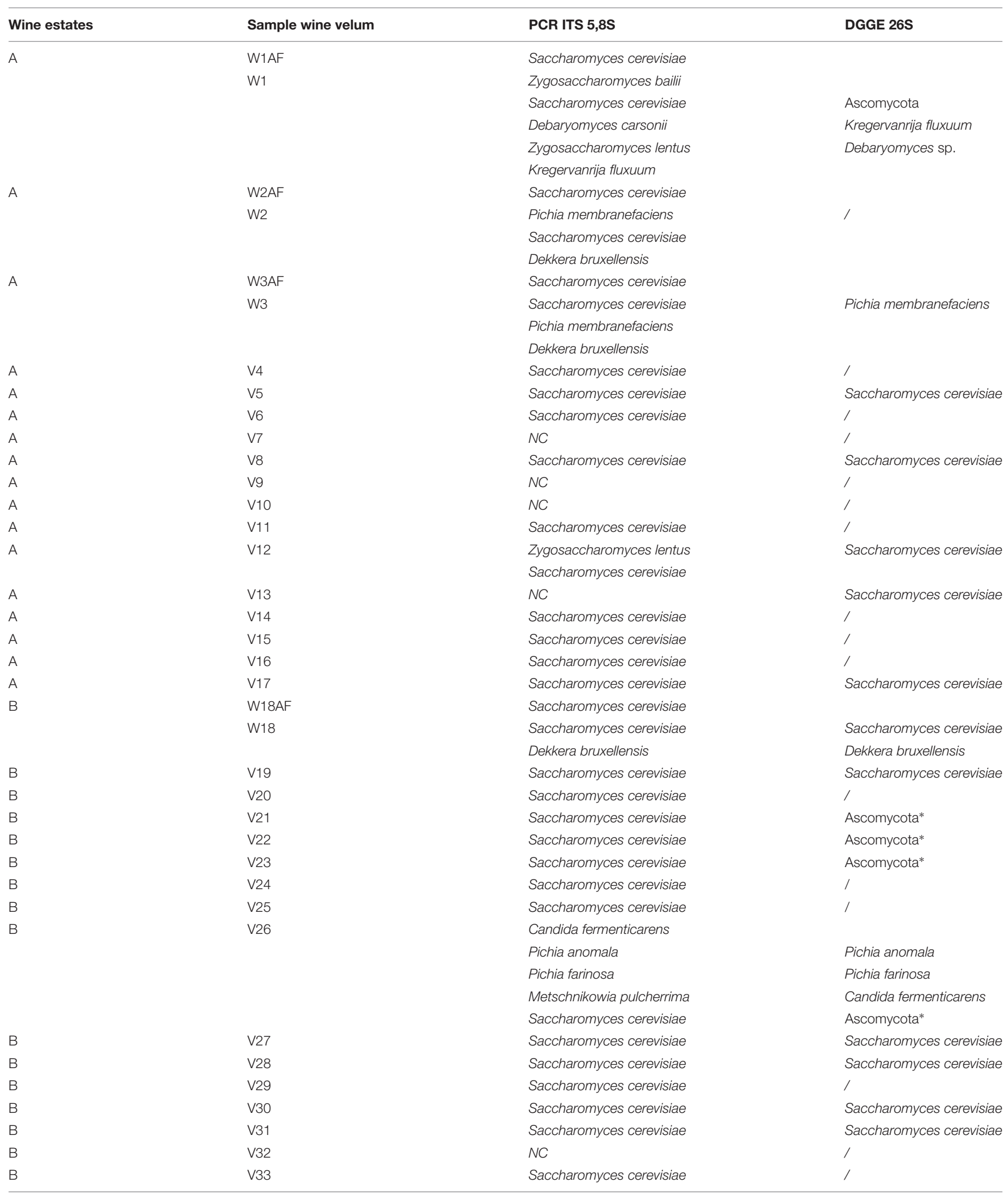

(Continued) 
TABLE 1 | Continued

\begin{tabular}{|c|c|c|c|}
\hline Wine estates & Sample wine velum & PCR ITS 5,8S & DGGE 26S \\
\hline$B$ & V34 & Saccharomyces cerevisiae & Saccharomyces cerevisiae \\
\hline \multirow[t]{2}{*}{$B$} & V35 & Saccharomyces cerevisiae & Dekkera bruxellensis \\
\hline & & Dekkera bruxellensis & \\
\hline$B$ & V36 & Saccharomyces cerevisiae & Saccharomyces cerevisiae \\
\hline \multirow[t]{2}{*}{$B$} & V37 & Saccharomyces cerevisiae & Saccharomyces cerevisiae \\
\hline & & Dekkera bruxellensis & Dekkera bruxellensis \\
\hline$B$ & V38 & Saccharomyces cerevisiae & Saccharomyces cerevisiae \\
\hline$B$ & V39 & NC & Saccharomyces cerevisiae \\
\hline$B$ & V40 & NC & Saccharomyces cerevisiae \\
\hline$B$ & V41 & NC & Saccharomyces cerevisiae \\
\hline
\end{tabular}

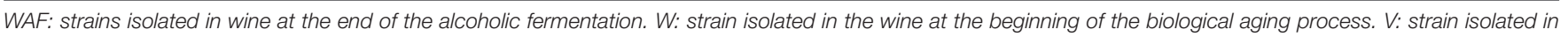
the velum. NC: not cultivable. *Ascomycota: Unidentifiable yeast, 100\% similar by blast for V21-V22-V23-V26-W1 26S ribosomial RNA gene.
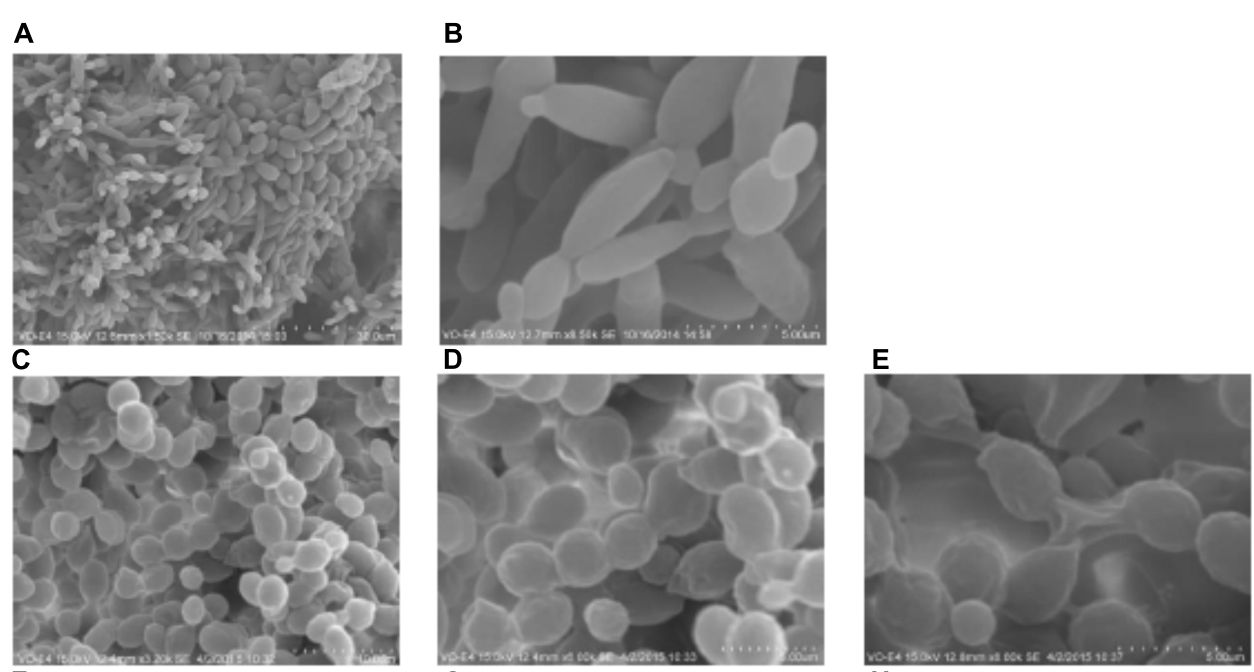

$\mathbf{F}$
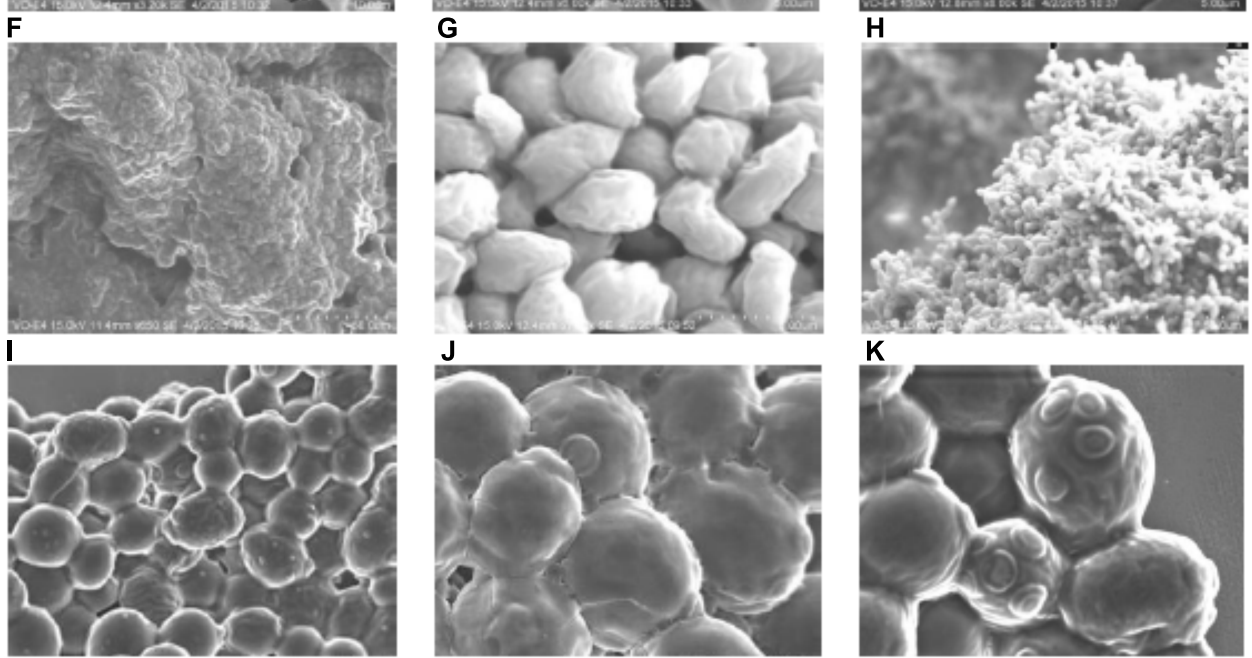

FIGURE 2 | Scanning electron microscopy of velum: (A) $\times 2,000$ (B) $\times 8,500$ ovoid yeast and elongated pseudomycelium yeast; (C) $\times 3,000$ (D) $\times 6,000$ (E) $\times 8,000$ yeast biofilm where yeasts are present in short chains of several cells; $\mathbf{( F )} \times 650 \mathbf{( G )} \times 7,000 \mathbf{( I )} \times 5,000 \mathbf{( J , K )} \times 10,000$ very dense biofilm with network of yeast, with all yeast cells embedded in an extracellular matrix; $\mathbf{( H )} \times 1,000$ velum in $3 \mathrm{D}$ like structure is visible formed by a sequence of ovoid cells attached together by their pole in an apparently disorganized manner. 
$72^{\circ} \mathrm{C}$ for $1 \mathrm{~min}$. The presence of the deletion was detected by capillary electrophoresis on a MultiNA MCE 202 (Shimadzu, France).

\section{Cluster Analysis of the Strains}

The inter delta sequence patterns obtained after capillary electrophoresis were used to construct a presence/absence matrix, taking into account the total number of different bands observed. All visible bands were assigned a number based on relative position to the DNA ladder. Each position was then assigned a " 0 " or a " 1 " to indicate the absence or presence of the band, respectively. Then, $0 / 1$ matrix was used to generate a dissimilarity dendrogram based on the Dice coefficient using the UPGMA algorithm with XLstat (Addinsoft, Inc.).

\section{RESULTS AND DISCUSSION}

Flor yeasts have been extensively studied from the genomic, proteomic, and metabolomics angles (Alexandre, 2013; Legras et al., 2016), because they provide an interesting biological model for studying the adaptation of yeasts to a specific niche. However, little information exists on the dynamics of yeast from alcoholic fermentation until the end of the biological aging process. Jura "vin jaune" is a sherry like wine whose aging lasts 6 years in partly filled barrels that allow a velum yeast to develop. The objective of the present study was to investigate the nature of the yeast present at the end of alcoholic fermentation until the end of the 6-year aging process.

\section{Flor Yeast Velum Characteristics}

Two thousand five hundred and sixty-five yeast strains were isolated from two different cellars in Jura vineyard (France) from 41 Savagnin Jura wines from the 2007 to 2013 vintages. Sampling was done in winter, summer, and autumn. Several examples of the nature of the velum are given Figure 1. Surprisingly, this is the first morphological characterization of velum. Indeed, despite the numerous studies on flor yeast, there are no detailed descriptions of the velum present on wines. Figure 1 shows the extraordinary diverse nature of the velum found. White, cream, yellow, pink, deep gray, brown and black velums were observed. These velums were not homogenous, and wines could be completely covered Figures $\mathbf{1 C}, \mathbf{F}$ or partly covered by velum (Figures $\mathbf{1 A}, \mathbf{B}, \mathbf{D}-\mathbf{F}$ ). This might reflect the age of the velum. When the velum starts to grow, it forms a small island on the surface of the wine (Figure 1G) and then expands to cover the entire surface of the wine (Figure 1F). Different velum morphologies could also be observed, some appear smooth (Figure 1F), others are granular (Figure 1C), while others present wrinkles (ruffled pattern) (Figures 1B,H).

Figure 1A presents kinds of blisters which might reflect the effect of carbon dioxide entrapped in the velum. Another characteristic of this velum is the presence of different colors which might reflect the presence of different microorganisms. For example, in Figure 1F white spots are present on the deep gray velum; in Figure 1E a mix of gray, black yellow and white can be seen while Figure 1D is characterized by a mix of white,

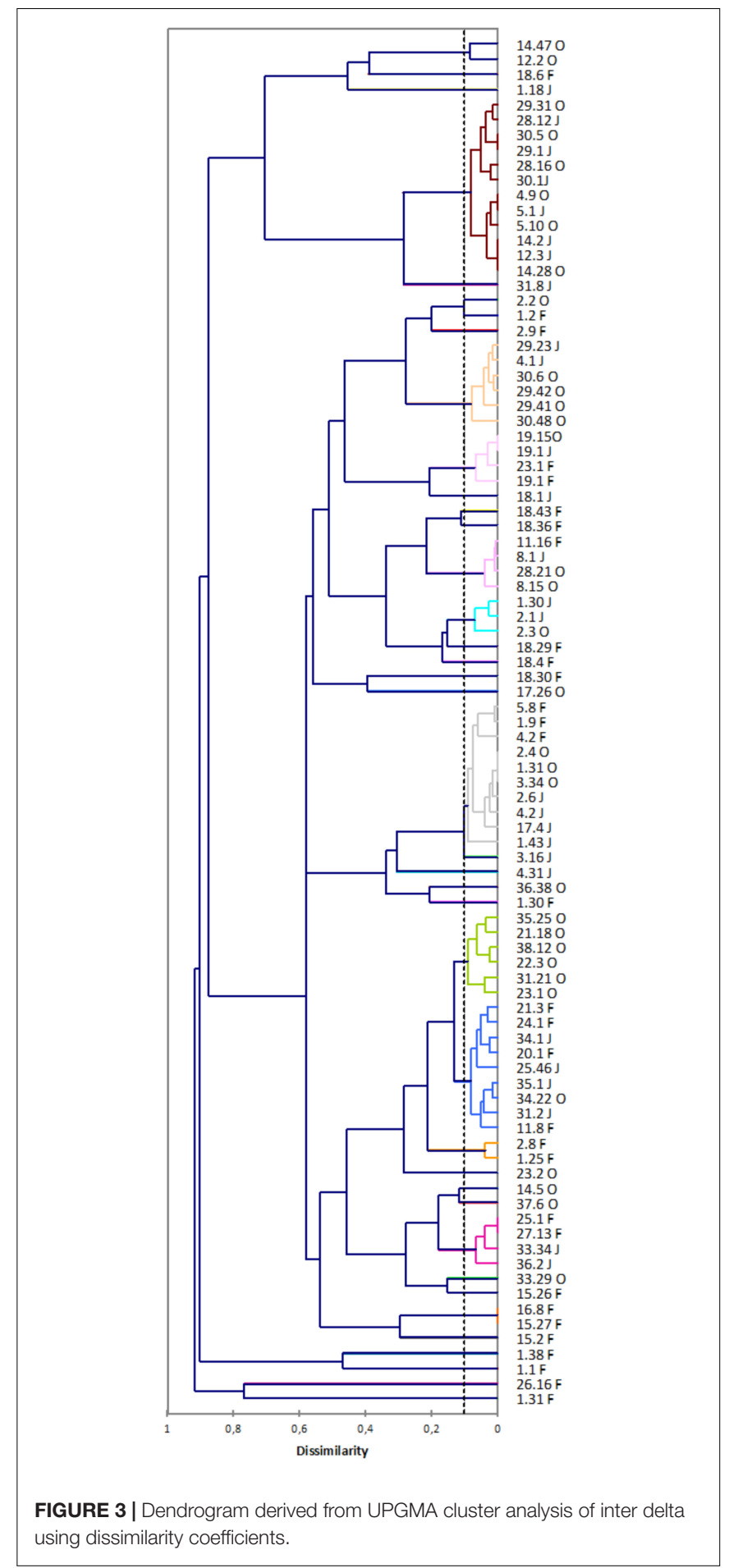

brown, and yellow. Thus, our study revealed that contrary to what is reported in the literature (Charpentier et al., 2009) velums are not only gray or white.

\section{Flor Yeast Species Identification}

Microorganisms present in the velum were isolated either on bacteria or yeast medium. No bacteria could be recovered from 
TABLE 2 | Identification of all the Saccharomyces cerevisiae strains isolated in all the velum according to their ITS RFLP profile.

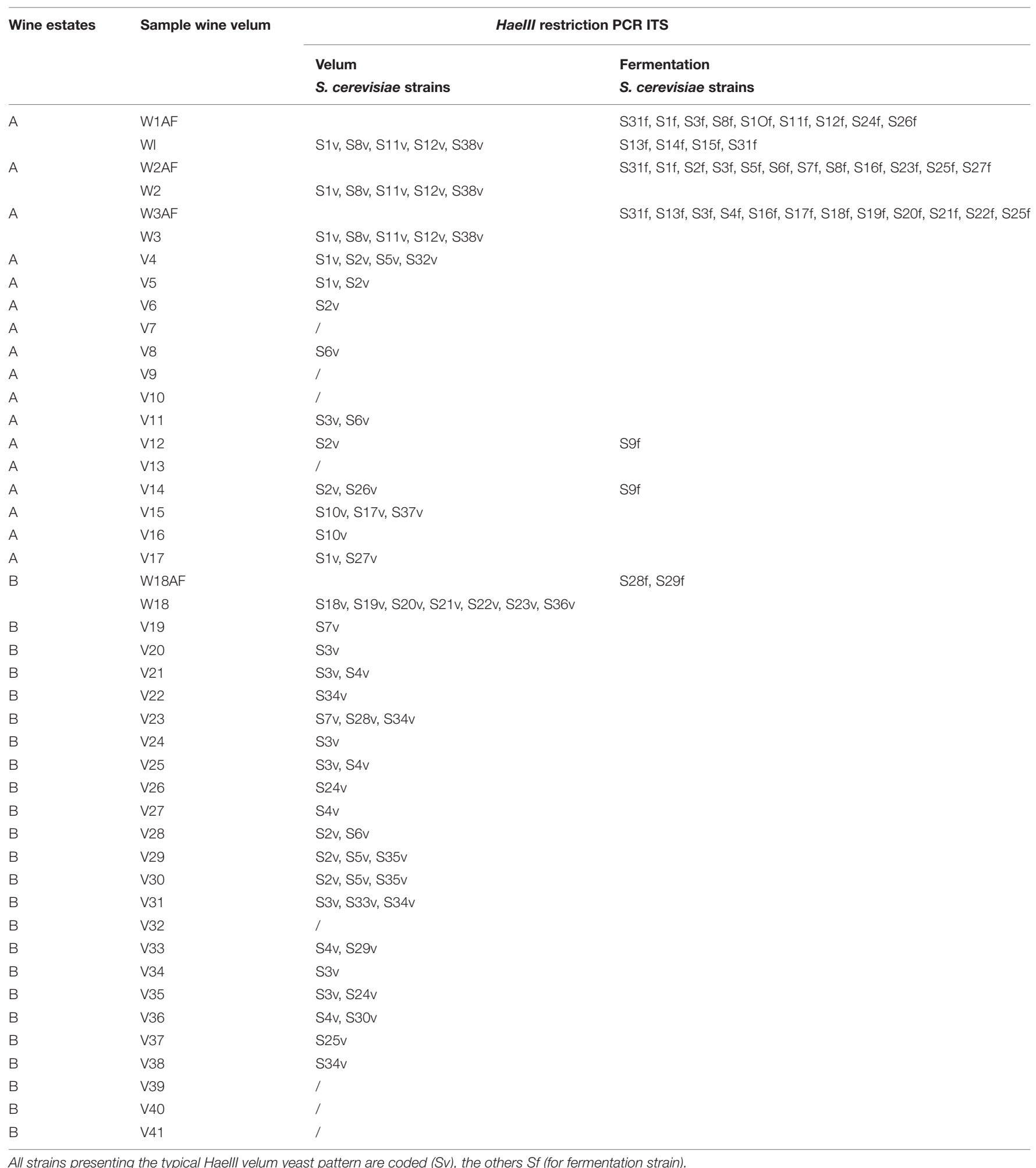

any of the velums sampled. Two thousand five hundred and sixty-five yeasts were isolated from these velums to identify the nature of the species present. However, despite the use of different media, some of the isolates were not able to recover growth. For these reasons, DGGE was used to identify the species present in the velums. Table 1 groups the identification of the species present in wine at the end of alcoholic fermentation, after the transfer of the wine into barrels for biological aging, and in 
velum. Four different Savagnin Jura wines were sampled: three in wine estate $\mathrm{A}$ and one in wine estate B. As expected, at the end of alcoholic fermentation, $100 \%$ of the yeast present belonged to $S$. cerevisiae species (W1AF, W2AF W3AF, W18AF) (Table 1). After the transfer of the wine from tanks to barrels for biological aging, different species could be found, as shown by PCR-ITS and DGGE. As shown in Table $\mathbf{1}$ most of the yeasts present in the velum belonged to $S$. cerevisiae species, which support previous reports (Martinez et al., 1995; Ibeas et al., 1997; Charpentier et al., 2009; Pozo-Bayón and MorenoArribas, 2011). However, in rare cases different species could be identified in the same velum (Table 1). Velum V35 and V37 was composed of both $S$. cerevisiae and Dekkera bruxellensis while Velum V12 was formed with Zygosaccharomyces lentus together with $S$. cerevisiae. These results demonstrate that other wine yeast species can form biofilms and survive this harsh environment. The presence of such species that reflect wine alteration has already been reported (Ibeas et al., 1996; SuarezLepez and Inigo-Leal, 2004). The most important aspect of this study is that although most velums were composed of S. cerevisiae, they presented very different velum characteristics. This means that a single species can lead to different types of velum in terms of color, structure and surface characteristic. To explain these unexpected observations, we investigated the nature of the differences in velum morphology using scanning electron microscopy.

\section{Scanning Electron Microscopy of Velum}

Surprising images were obtained, highlighting huge differences between the biofilm structures of velums (Figure 2). Microscopic observations revealed distinct yeast morphologies (Figure 2A). Typical yeast shape-like cells (ovoid) together with elongated yeast could be observed (Figures 2A,B). This velum is composed of both S. cerevisiae and Dekkera bruxellensis and identified by the label ITS-RFLP (Table 1). Many different yeast morphologies were observed in the different velums under study. Figures 2C-E show a yeast biofilm in which yeasts are present in short chains of several cells. Yeast cells are recovered by an extracellular matrix (Figure 2D) and connected by an extracellular material (Figure 2E). This biofilm characteristic has already been observed previously (Zara et al., 2009). However, a third type of velum biofilm never reported before is presented (Figures 2F,G,I-K). A very dense network of yeast is observed for this biofilm, with all the yeast cells embedded in an extracellular matrix. Finally, Figure $\mathbf{2 H}$ shows another model of biofilm in which a $3 \mathrm{D}$ like structure is visible, formed by a sequence of ovoid cells attached together by their pole in an apparently disorganized manner. Our results show that there are extensive phenotypic variations between yeasts regarding biofilm morphology though they all belong to $S$. cerevisiae species except the biofilm shown in Figures 2A,B.

Variations in ploidy have been reported to play a key role in biofilm phenotypes (Hope and Dunham, 2014) and might explain the differences observed. However, according to Legras et al. (2014) most of the flor strains (70 flor strains studied from different countries) are diploid, which does not support the idea that biofilm phenotypic differences are linked to ploidy. On the other hand, aneuploidies are considered to be a potential mechanism allowing adaptation to flor aging (Guijo et al., 1997; Infante et al., 2003), but according to Legras et al. (2014) there is no substantial aneuploidy in flor yeast.

Differences in velum characteristics might be linked to different $S$. cerevisiae strains, therefore all the S. cerevisiae strains sampled from wines (at the end of alcoholic fermentation before velum formation), at the beginning of the biological aging process and velum formation were genotyped.

\section{Flor Yeast Strain Genotyping}

Among the 2,025 isolates belonging to $S$. cerevisiae determined by ITS RFLP, we found 69 different genotypes determined by subjecting inter delta data to clustering analysis (Figure 3). Among these 69 different S. cerevisiae strains, 38 of them were velum yeasts according to their ITS RFLP profile (Table 2). Indeed, in velum yeast an insertion in the ITS1 region led to an additional HaeIII site which allowed differentiating

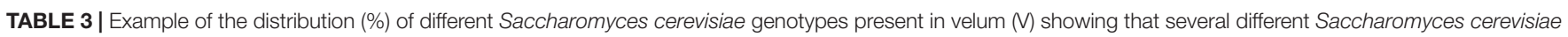
strains could be present in a same velum.

\begin{tabular}{|c|c|c|c|c|c|c|c|c|c|c|}
\hline & \multicolumn{10}{|c|}{ Velum } \\
\hline & & V4 & V11 & V14 & V15 & V23 & V28 & V29 & V30 & V31 \\
\hline \multirow{11}{*}{$\begin{array}{l}\text { Saccharomyces cerevisiae } \\
\text { genotype }\end{array}$} & S1V & 88 & & & & & & & & \\
\hline & $\mathrm{S} 2 \mathrm{~V}$ & & & 81 & & & 71 & 90 & 75 & \\
\hline & S3V & & 34 & & & & & & & 84 \\
\hline & S5v & 8 & & & & & & 10 & & \\
\hline & S6v & & 66 & & & & 29 & & 25 & \\
\hline & S9f & & & 13 & & & & & & \\
\hline & S26v & & & 6 & & & & & & \\
\hline & S28v & & & & & 50 & & & & \\
\hline & S32v & 4 & & & & & & & & \\
\hline & S33v & & & & & & & & & 16 \\
\hline & S34v & & & & & 50 & & & & \\
\hline
\end{tabular}


flor-S. cerevisiae from classical S. cerevisiae (Esteve-Zarzoso et al., 2004; Charpentier et al., 2009). It is noteworthy that none of the $S$. cerevisiae strains isolated at the end of the alcoholic fermentation (samples W1AF, W2AF, W3 AF, W18 AF) gave the specific flor-Saccharomyces cerevisiae HaeIII restriction pattern (Table 2). These results underline that the model proposed by Zara et al. (2005) might not be the general rule. Indeed, in their model, they propose that at the end of alcoholic fermentation, an increase of FLO11 expression following diauxic shift leads to an increase of cell surface hydrophobicity and consequently favors cell aggregation and biofilm formation. However, as shown here and as far as we know, flor yeasts have never been isolated in wine at the end of the alcoholic fermentation.

The second analysis of yeast strains present in wine was performed after the transfer of the wine into barrels, at the beginning of the biological aging process. While there was still no visible velum at that stage, most of the yeast strains

TABLE 4 | Example of the distribution (\%) of different Saccharomyces cerevisiae genotypes present in velum (V) showing the shift from one strain to another according to the season.

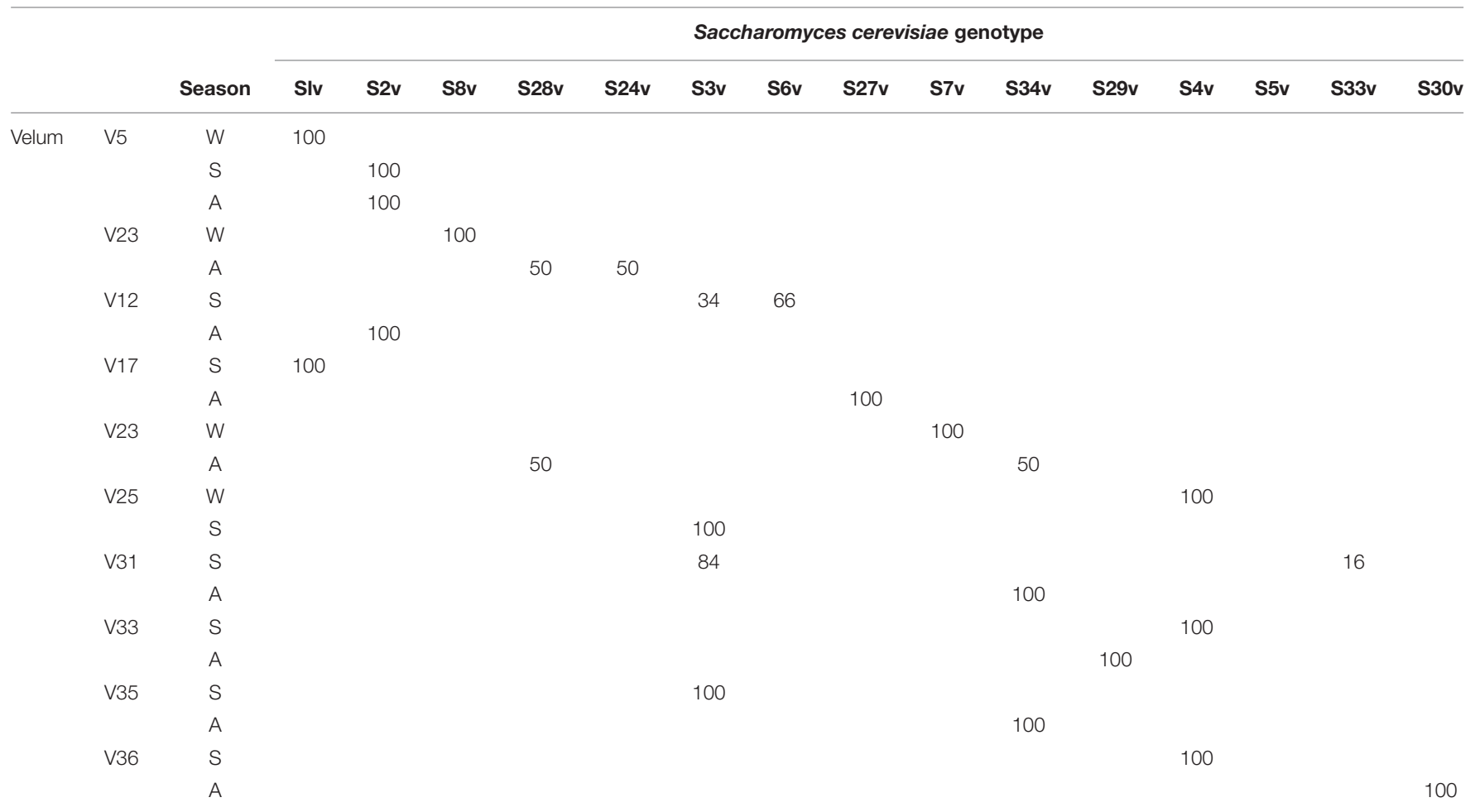

W, winter; S, summer; A, autumn.

TABLE 5 | Example of different Saccharomyces cerevisiae genotypes isolated in velum with different colors.

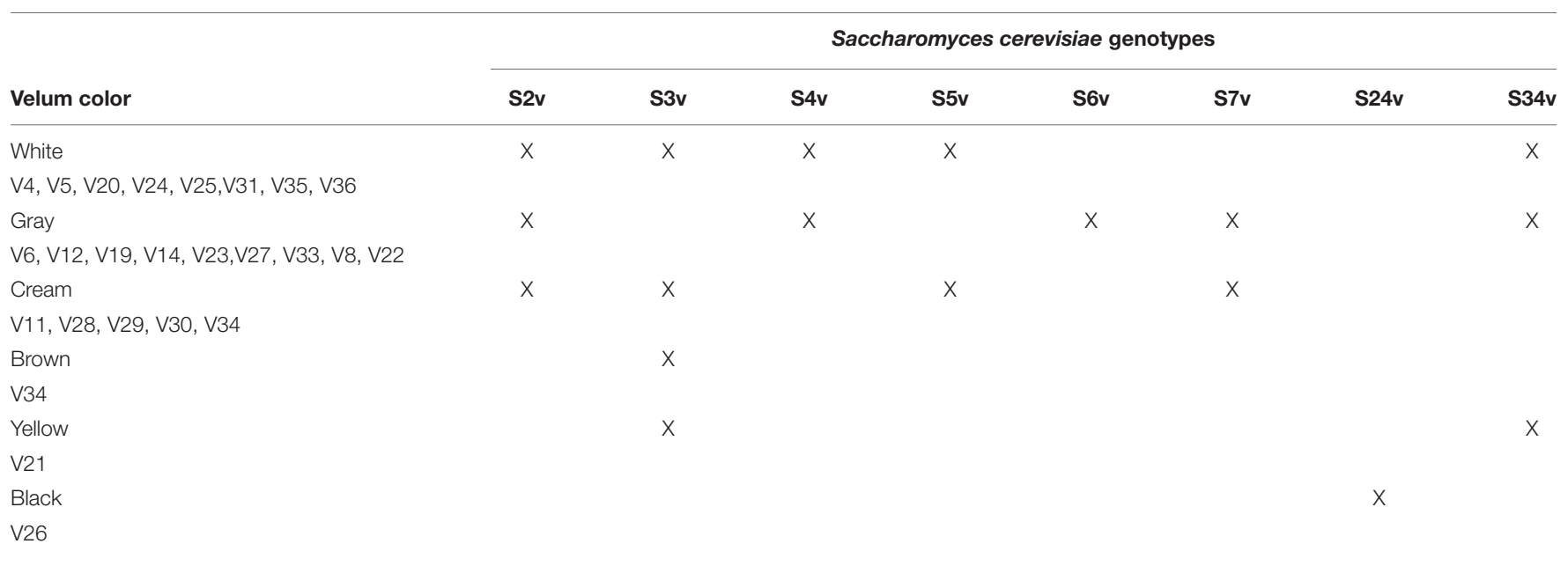


TABLE 6 | FLO11 promoter size and ORF length variations, velum color and thickness of various flor strains [55 clones belonging to 38 genotypes (S1v to S38v)].

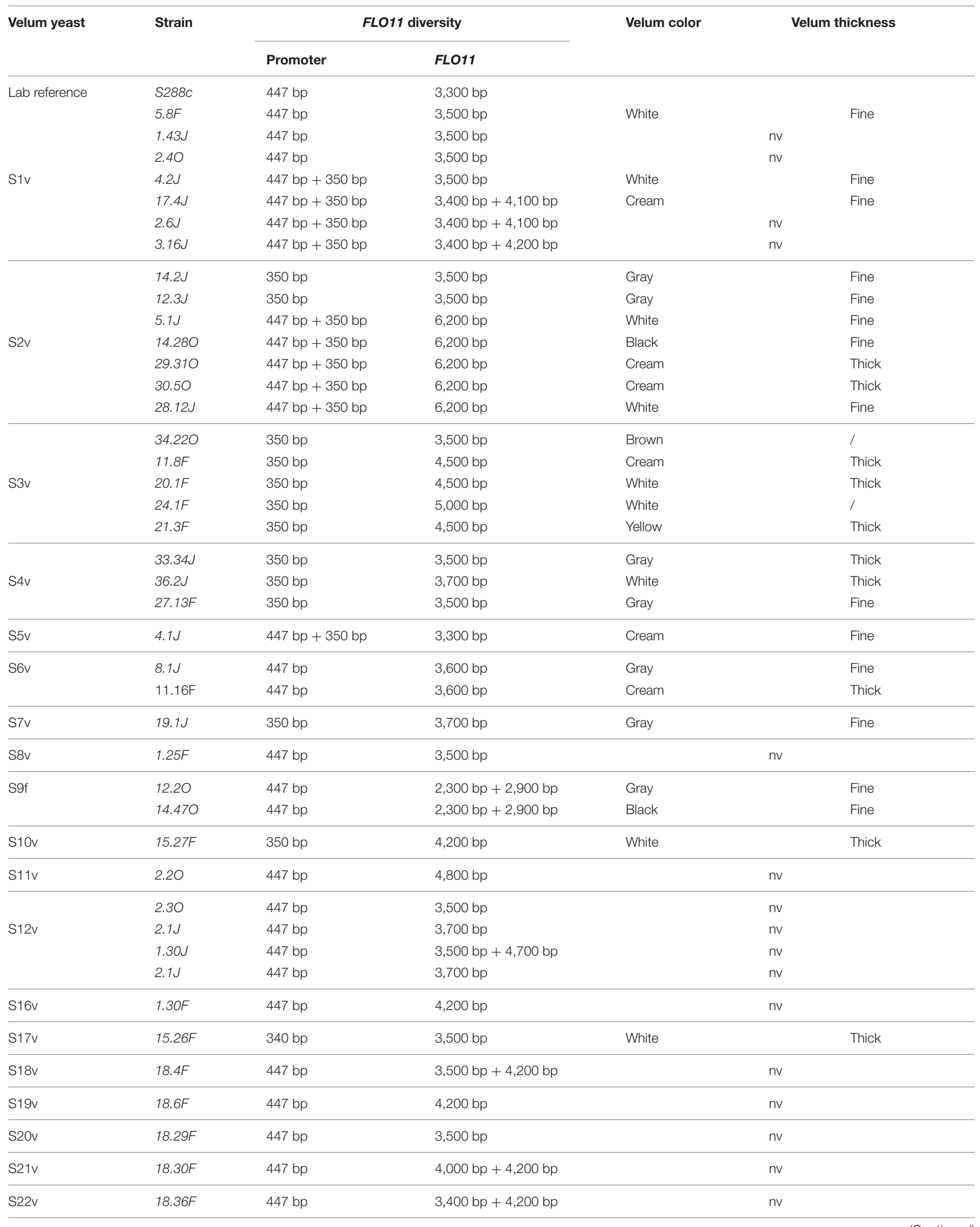


TABLE 6 | Continued

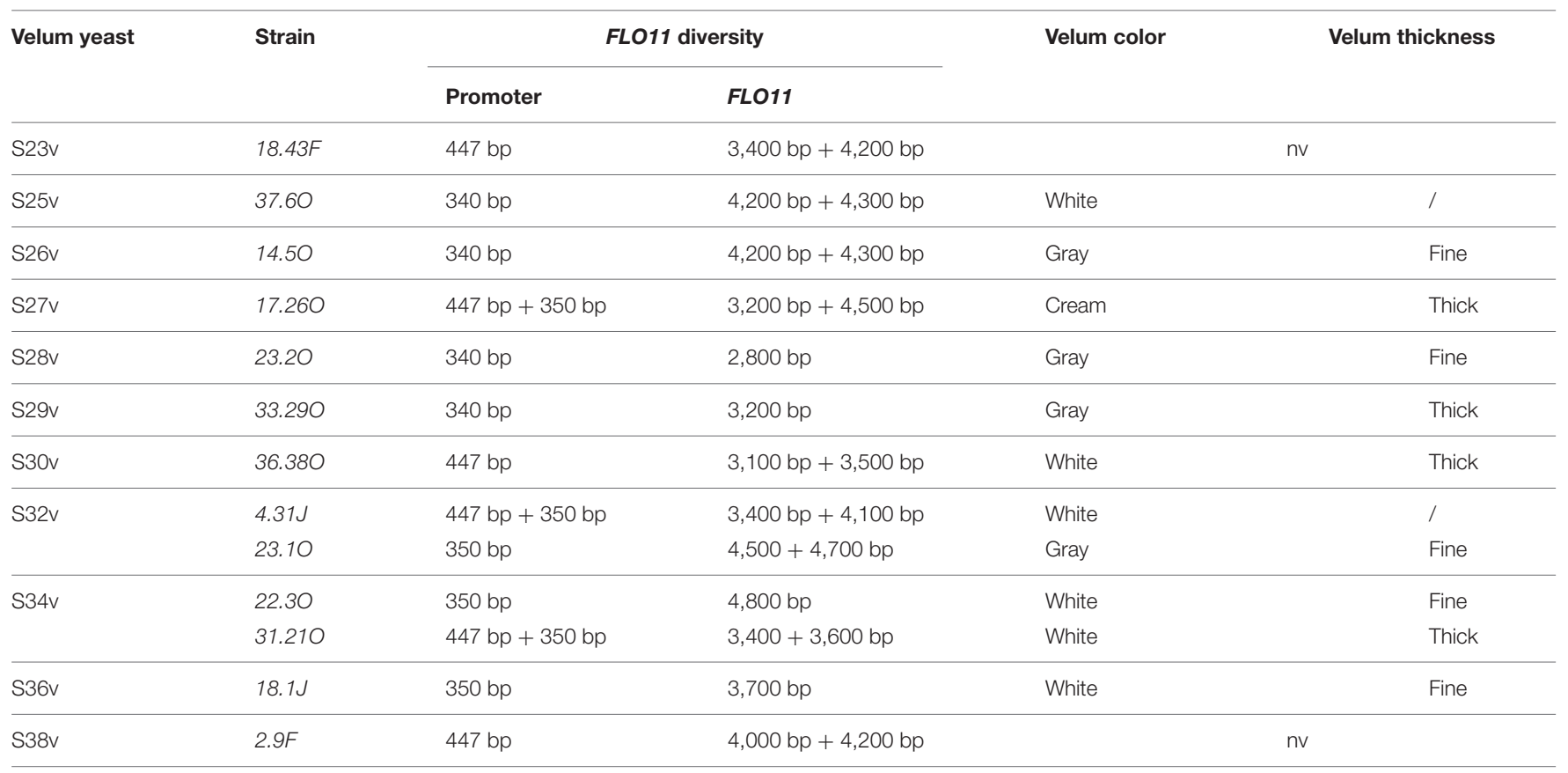

nv, No installed velum.

isolated belonged to $S$. cerevisiae species and most were florSaccharomyces yeasts (samples W1, W2, W3, W18) (Table 2). One exception could be observed in wine 1, where classical S. cerevisiae belonging to four different phenotypes were isolated (S13f, S14f, S15f, and S31f). This was not unexpected, since residual fermentation yeasts were present in wine during wine transfer. However, our results support the view that velum formation is due more to the implantation of flor yeast present in the cellar, barrels and materials. Indeed, ITS-RFLP profiles determined on all the $S$. cerevisiae strains isolated from velum (samples V4 to V41) demonstrated that except one strain (S9f) they all shared the common HaeIII restriction pattern of flor yeast (Table 2).

\section{Dynamics of Saccharomyces Genotypes During the Biological Process Aging}

To determine seasonal effects, the time of possible community shifts during aging, and the presence of any dominant genotype, we analyzed the frequency (\%) of all the S. cerevisiae genotypes according to the wine estate, the vintage, and the seasons in wines at the beginning of the aging process and in velums (Supplementary Table S1). For ease of reading, data where extracted from this important table to present data in Tables 3, 4 .

Table 3 clearly shows that velum could be formed by several different $S$. cerevisiae strains. For example velums V4, V11, V14, V15, V23, V28, V29, V30, and V31 possess two or three different S. cerevisiae strains. It was very puzzling to observe a shift from one strain to another during aging (Table 4). Indeed, velum V5 was composed of only one S. cerevisiae strain (S1v) for the sampling done in winter which was different from the strain genotype (S2v) present in the same velum in summer and autumn
(Table 4). The same behavior was observed for V23, V25. The same observations were made when comparing summer and autumn periods for velums V12, V17, V31, V33, V35, and V36 (Table 4). These results suggest that some flor yeasts are better adapted than others and could competitively displace them. This dynamic nature of $S$. cerevisiae populations has been observed during alcoholic fermentation (Frezier and Dubourdieu, 1992; Versavaud et al., 1995; Schuller et al., 2005) but never reported for flor yeast.

This $S$. cerevisiae dynamic might be explained by changes in environmental conditions during the four seasons such as temperature $\left(5-10^{\circ} \mathrm{C}\right.$ in the cellar in winter and $25-30^{\circ} \mathrm{C}$ in the cellar in summer: cellars for aging are under the roof) (Charpentier et al., 2002). Indeed, this succession revealed that environmental conditions drive community shifts. Some strains of $S$. cerevisiae may be better adapted to higher temperatures than others, explaining their occurrence during summer, for example. During aging, the velum can sink in the wine because the cells are not adapted to the medium and changing environmental conditions which allow a better adapted strain to colonize the medium and form a new velum composed of a different strain. Other original information revealed by our study is that the same strain could be observed in velums from different wines. For example, the genotype profile S3v (Supplementary Table S1) was found in velum from vintages 2008, 2010, 2011, 2012 and the genotype profile S2v (Supplementary Table S1) was found in velum from vintages 2009, 2011, 2012. We could also observe patterns of sporadic presence, absence and reoccurrence. Profile S7v was absent from vintage 2008, appeared for the first time in 2010, though was absent from the 2011 velum and then reappeared in 2012. A similar dynamic pattern could be observed for profile S2v. These results reflect that there are a 


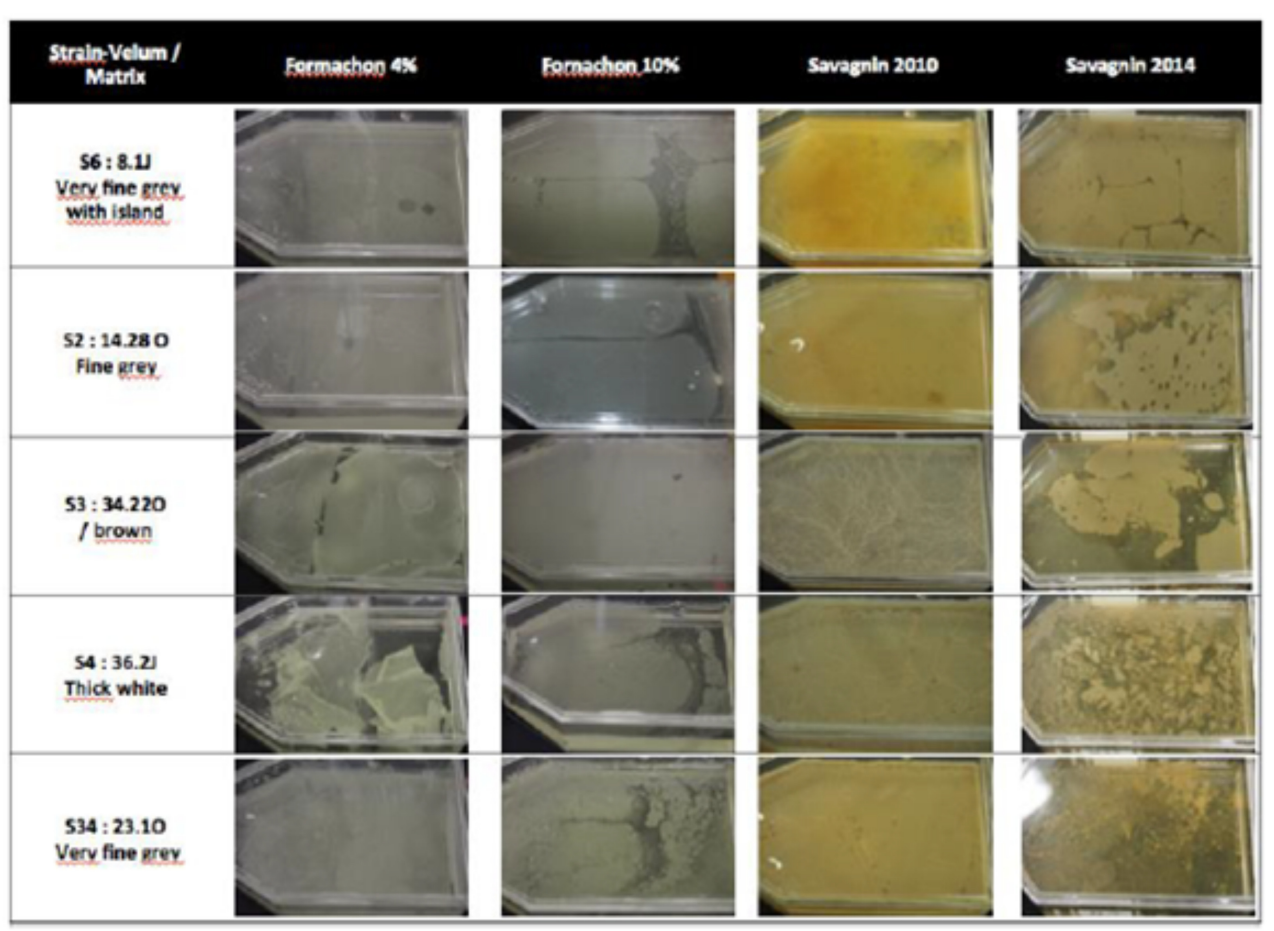

FIGURE 4 | Structure and color of velum on different matrixes: grape, juice medium (Fornachon, 1953), synthetic [Fornachon 4\% and 10\% (v/v) ethanol] and two Savagnin wines (vintage 2010 and 2014) observed after 1 month. The inoculated strains are from different velums: S6: strain 8.1 J from very fine gray velum with islands; S2: $14.2 \mathrm{O}$ strain from fine gray velum; S3: $32.22 \mathrm{O}$ from brown velum; S4: 36.2J strain from thick white velum and S34: 23.10 strain from very fine gray velum.

few dominant strains that are better adapted to the wine than others. Another surprising observation was the fact that the same $S$. cerevisiae genotype profile was found in velums with very different surface characteristics (Table 5). For example, $S$. cerevisiae profile S3v was found in velum with yellow (V21), white (V20, V25, V36), cream (V11), and brown colors and with different structures. One explanation could be that color reflects the evolution of the velum linked both to aging and wine composition. Indeed, during aging wine phenolic compounds oxidized (Danilewicz, 2012) and could be adsorbed by yeast cell walls which would stain the cells (Vasserot et al., 1997). Depending on wine composition, this oxidation might be more or less considerable, which could explain the color nuances from white to yellow and brown. Regarding velum structure differences, these could reflect differences in cell density, wine movement inside the barrels due to changes of the atmospheric pressure and Brownian movements due to temperature variation. However, strains isolated in thick white, yellow or brown velum were never isolated in thin gray or black velums which confirms previous results (Charpentier et al., 2009).

Supplementary Table S1 also reveals that although very rare, one strain that did not present the typical HaeIII (S9f) profile was present at $100 \%$ and $12 \%$ in two different velums from 2009 and 2011, respectively (Table 2). Such observations were reported before in Jura flor yeast (Charpentier et al., 2009).

All flor yeasts were isolated from two different wine estates $54 \mathrm{~km}$ away from each other. It is noteworthy that they did not share any common S. cerevisiae flor yeast. This result supports the existence of the geographic distribution of yeast profiles observed previously (Charpentier et al., 2009).

\section{Phenotype and Genotype Correlation}

We determined both the size of the FLO11 gene and IRC1 region of 55 Saccharomyces clones corresponding to 38 different strains according to interdelta profiles (Table 6). The amplification of a short sequence of ICR1 ncRNA for all flor-Saccharomyces gave two different sizes, $447 \mathrm{bp}$ and $350 \mathrm{bp}$, corresponding respectively to the wild and $111 \mathrm{bp}$ deletion of the ICR 1 sequence, as previously reported (Fidalgo et al., 2006). Interestingly, some strains carried a wild and a deleted allele. On 52 isolates, 12 possessed both alleles, 19 possessed only the allele with the deletion in the ICR1ncRNA region and 21 possessed only the full length ICR1ncRNA allele (Table 6). The presence of both alleles in flor yeast has already been reported for Hungary isolated flor yeast (Legras et al., 2014). However, contrary to our observations, the authors did not find either allele in any of the Jura flor yeast isolates. The length of the core region of FLO11 gene was sequenced for all the isolates and its size varied from 2.8 to $6.2 \mathrm{~kb}$. These results agree with a previous report (Legras et al., 2014). Most of our isolates possessed a FLO11 sequence longer than the sequence of wine yeast whose average size was $2.9 \mathrm{~kb}$ using the same primers (Legras et al., 2014). Regarding the promoter region, many isolates were heterozygote at the FLO11 locus, which is in line with previous reports (Legras et al., 2014). It 
is noteworthy that different isolates that had been characterized as being the same yeast strain based on interdelta PCR analysis, could have different FLO11 promoters and lengths (Table 6). Indeed, not all the clones (14.2J, 12.3 J, 5.1J, 14.28O, 29.31O, $30.5 \mathrm{O}, 28.12 \mathrm{~J})$ sharing the profile $\mathrm{S} 2 \mathrm{v}$ had the same FLO11 promoter and/or ORF length (Table 6). The same phenomenon could be observed for clones sharing the same interdelta profile S1v.

Interestingly, among the strains isolated in the velums, two clones $(12.2 \mathrm{O} ; 14.47 \mathrm{O})$ sharing the same genotype (S9f) present in velums 12 and 14 had neither a long FLO11 nor a deletion in ICR1 (Table 6) and, as mentioned before, they did not have the typical HaeIII profile. However, they were able to form a velum. Although a very rare event, this is not surprising. Indeed, although the expression of FLO11 has been shown to be the key event for biofilm formation, other genes, i.e., FLO5, FLO9, FLO10 encoding Flo5p, Flo9p, and Flo10p confer cellcell adhesion. Moreover, it cannot be excluded that FLO11 expression and cell hydrophobicity could be linked to factors other than ICR1 deletion or a long FLO11 gene. Indeed, the regulation of FLO11 is complex and depends on different specific pathways: the cAMP-protein kinase A (PKA) pathway; the mitogen-activated protein kinase (MAPK) pathway; and the TOR pathway (Braus et al., 2003; Vinod et al., 2008). Moreover, it has been shown that biofilm formation is also dependent on fatty acid biosynthesis (Zara et al., 2012). Fierro-Risco et al. (2013) also reported that the expression of stress-related genes (SOD1, SOD2, HSP12) could favor velum formation and thickness. More recently, Coi et al. (2017) demonstrated that flor yeasts possess specific SFL1, RGA2 alleles that enhance flor formation. These results support the view that although FLO11 polymorphism is an important characteristic of flor yeast and plays a key role in velum formation, other genes might be involved, and that the environment probably influences the nature of the velum.

To check the link between yeast flor phenotypes, especially the thickness of the velum and the polymorphism of FLO11, we compared the size of ICR1 and FLO11 with the velum characteristics. As shown in Table 6, there is no clear link between yeast phenotypes, especially the thickness of the velum and the polymorphism of FLO11.

Strains with a wild type ICR1 ncRNA and a long Flo11p are expected to develop thin velum (Legras et al., 2014). However, in our study, $S$. cerevisiae clones classified in genotype S3v $(11.8 \mathrm{~F}, 20.1 \mathrm{~F}$, and $21.3 \mathrm{~F}$ possessed a deletion in the ICR1nc RNA sequence but were isolated from thick velum (Table 6). On the other hand, S6 8.1J and S1 5.8F was isolated from thin velum but possessed a wild ICR 1 allele (Table 6). Strain 33.290 formed thick velum and possessed the deletion in its ICR1 promoter. These results show that the presence of the $111 \mathrm{bp}$ deletion in the ICR1 ncRNA was not always related to thin velum, as suggested previously (Legras et al., 2014). Our results support recent findings in which flor formation ability was shown to be variable in a flor strain with a specific deletion in the promoter of the FLO11 gene (Kishkovskaia et al., 2017).

In these conditions, we wondered why some velums were thin and others thick. We hypothesized that the velum thickness might be related to the wine matrix. Indeed, according to our results, the same flor yeast could give different velums. For example, two isolates, namely 14.280 and 29.310 which were isolated in two different velums, one thin and one thick, presented the same inter delta pattern and the same ICR1 and FLO11 sequence. The same characteristics could be observed for the two strains $8.1 \mathrm{~J}$ and $11.16 \mathrm{~F}$ (Table 6). These results suggest that the same strain in two different matrixes can give different velums.

In order to confirm this, we inoculated different synthetic wines and Savagnin wine (vin jaune) with five different yeast strains 34.22O, 36.2J, 23.1O, 8.1J, 14.28O) possessing either a deletion in the promoter or a long FLO11 gene or both (Figure 4). The color of the velum depended on both the medium and the age of the wine (Figure 4). While strain 34.220 gave a thick velum as expected (ICR1 deletion), strain 8.1J sampled in a fine gray velum gave a thin pale gray velum in Fornachon medium [4 and 10\% (v/v)] and a thick yellow/brown velum in a 2010 Savagnin wine and a thick white/cream velum in a 2014 Savagnin wine. Strain 14.280 gave a thick and thin velum in Fornachon and Savagnin, respectively. Strain 36.2J developed a thick pale gray velum in Fornachon 4\%, a thin pale gray velum in Fornachon (10\%) and a thick yellow velum in Savagnin 2010. Interestingly, the aspect of the velum differed as a function of the medium. While the velum developed with strain $34.22 \mathrm{O}$ was very smooth in Fornachon $4 \%$, the velum presented wrinkles (ruffled pattern) in Savagnin 2010. Differences in velum aspects could also be observed for strain 36.2J when comparing all media, the major difference being between Fornachon and Savagnin Wine. These observations could be explained by the fact that biofilm formation is affected by nitrogen availability (Mauricio et al., 2001; Berlanga et al., 2006; Zara et al., 2011). Inositol availability has also been shown to influence biofilm formation (Zara et al., 2012). Thus, velum formation and velum characteristic are influenced by complex mechanisms involving both the genetic background of the yeast and wine composition.

\section{CONCLUSION}

Our results show that Savagnin wine velums present very different characteristics never reported before in terms of color and morphology. Scanning electron microscopy analysis revealed remarkable differences in biofilm structure with distinct yeast morphologies and the presence of extracellular matrix. Despite all the differences observed, flor yeast genotyping demonstrated that most of the strains present in the velums belong to $S$. cerevisiae species and present the typical HaeIII ITS-RFLP flor yeast pattern. The genotyping analyses also demonstrate that a velum could be formed either of several different $S$. cerevisiae strains or one strain. Furthermore, a same strain could be present in velums presenting very different characteristics, supporting the view that wine composition plays a key role on velum characteristics. Our study also revealed population shifts during aging which reflects the fact that a strain could competitively displace another strain which could be linked to environmental changes during aging such as drastic temperature changes for example. 
Finally, we confirmed in the present study the polymorphism of FLO11 gene but we did not find any correlation between velum characteristic and FLO11 polymorphism.

\section{AUTHOR CONTRIBUTIONS}

VD-V made all the laboratory experiments and made some wine sampling. HA sampled the wine, designed the experiments, and wrote the article. Interpretations were done by VD-V and $\mathrm{HA}$.

\section{FUNDING}

This work was supported by the Conseil Régional de Bourgogne through the plan d'actions régional pour l'innovation (PARI) and

\section{REFERENCES}

Alexandre, H. (2013). Flor yeasts of Saccharomyces cerevisiae-their ecology, genetics and metabolism. Int. J. Food Microbiol. 167, 269-275. doi: 10.1016/j. ijfoodmicro.2013.08.021

Aranda, A., del Querol, A., and Olmo, M. L. (2002). Correlation between acetaldehyde and ethanol resistance and expression of HSP genes in yeast strains isolated during the biological aging of sherry wines. Arch. Microbiol. 177, 304-312. doi: 10.1007/s00203-001-0391-1

Bakalinsky, A. T., and Snow, R. (1990). The chromosomal constitution of wine strains of Saccharomyces cerevisiae. Yeast 6, 367-382. doi: 10.1002/yea.320060503

Berlanga, T. M., Millàn, C., Mauricio, J. C., and Ortega, J. M. (2006). Influence of nitrogen on the biological aging of sherry wine. J. Sci. Food Agric. 86, 2113-2118. doi: $10.1002 /$ jsfa. 2584

Braus, G. H., Grundmann, O., Bruckner, S., and Mosch, H. U. (2003). Amino-acid starvation and Gcn4p regulate adhesive growth and FLO11 gene expression in Saccharomyces cerevisiae. Mol. Biol. Cell 14, 4272-4284. doi: 10.1091/mbc.e0301-0042

Capece, A., Granchi, L., Guerrini, S., Mangani, S., Romaniello, R., Vincenzini, M., et al. (2016). Diversity of Saccharomyces cerevisiae strains isolated from two italian wine-producing regions. Front. Microbiol. 7:1018. doi: 10.3389/fmicb. 2016.01018

Charpentier, C., Colin, A., Alais, A., and Legras, J.-L. (2009). French Jura flor yeasts: genotype and technological diversity. Antonie Van Leeuwenhoek 95, 263-273. doi: 10.1007/s10482-009-9309-8

Charpentier, C., Dos Santos, A.-M., and Feuillat, M. (2002). Contribution à l'étude du métabolisme des levures à voile dans l'élaboration des vins jaunes du Jura. Rev. Fr. Enol. 195, 33-36.

Cocolin, L., Bisson, L. F., and Mills, D. A. (2000). Direct profiling of the yeast dynamics in wine fermentations. FEMS Microbiol. Lett. 189, 81-87. doi: 10. $1111 /$ j.1574-6968.2000.tb09210.x

Coi, A. L., Bigey, F., Mallet, S., Marsit, S., Zara, G., Gladieux, P., et al. (2017). Genomic signatures of adaptation to wine biological ageing conditions in biofilm-forming flor yeasts. Mol. Ecol. 26, 2150-2166. doi: 10.1111/mec.14053

Danilewicz, J. C. (2012). Review of oxidative processes in wine and value of reduction potentials in enology. Am. J. Enol. Vitic. 63, 1-10. doi: 10.5344/ajev. 2011.11046

Eldarov, M. A., Beletsky, A. V., Tanashchuk, T. N., Kishkovskaya, S. A., Ravin, N. V., and Mardanov, N. V. (2018). Whole-genome analysis of three yeast strains used for production of sherry-like wines revealed genetic traits specific to flor yeasts. Front. Microbiol. 9:965. doi: 10.3389/fmicb.2018.00965

Esteve-Zarzoso, B., Belloch, C., Uruburu, F., and Querol, A. (1999). Identification of yeasts by RFLP analysis of the 5,8S rRNA gene and the two ribosomal internal transcribed spacers. Int. J. Syst. Bacteriol. 49, 329-337. doi: 10.1099/0020771349-1-329 the European Union through the PO FEDER-FSE Bourgogne 2014/2020 programs.

\section{ACKNOWLEDGMENTS}

We would like to acknowledge Aline Bonnotte from DImaCell plateforme and Marie-Laure Leonard from ESIREM and ARCEN platform, for providing microscopy images.

\section{SUPPLEMENTARY MATERIAL}

The Supplementary Material for this article can be found online at: https://www.frontiersin.org/articles/10.3389/fmicb. 2018.02235/full\#supplementary-material

Esteve-Zarzoso, B., Fernandez-Espinar, T., and Querol, A. (2004). Authentication and identification of Saccharomyces cerevisiae 'flor' yeast races in sherry ageing. Antonie Van Leeuwenhoek 85, 151-158. doi: 10.1023/B:ANTO.0000020282. 83717.bd

Esteve-Zarzoso, B., Peris-Toran, M. J., Garcia-Maiquez, E., Uruburu, F., and Querol, A. (2001). Yeasts population dynamics during the fermentation and biological aging of sherry wines. Appl. Environ. Microbiol. 67, 2056-2061. doi: 10.1128/AEM.67.5.2056-2061.2001

Fidalgo, M., Barrales, R. R., Ibeas, J., and Jimenez, J. (2006). Adaptive evolution by mutations in the FLO11 gene. Proc. Natl. Acad. Sci. U.S.A. 103, 11228-11233. doi: $10.1073 /$ pnas.0601713103

Fierro-Risco, J., Rincon, A. M., Benitez, T., and Codon, A. C. (2013). Overexpression of stress-related genes enhances cell viability and velum formation in Sherry wine yeasts. Appl. Microbiol. Biotechnol. 97, 6867-6881. doi: $10.1007 / \mathrm{s} 00253-013-4850-9$

Fornachon, J. G. M. (1953). Studies on the Sherry Flor. Adelaide: Australian Wine Board.

Frezier, V., and Dubourdieu, D. (1992). Ecology of yeast strain Saccharomyces cerevisiae during spontaneous fermentation in a Bordeaux winery. Am. J. Enol. Vitic. 43, 375-380.

Guijo, S., Mauricio, J. C., Salmon, J. M., and Ortega, J. M. (1997). Determination of the relative ploidy in different Saccharomyces cerevisiae strains used for fermentation and 'flor' film ageing of dry sherry-type wines. Yeast 13, 101-117. doi: 10.1002/(SICI)1097-0061(199702)13:2<101::AID-YEA66>3.0.CO;2-H

Hope, E. A., and Dunham, M. J. (2014). Ploidy-regulated variation in biofilmrelated phenotypes in natural isolates of Saccharomyces cerevisiae. G3 4, 17731786. doi: $10.1534 / \mathrm{g} 3.114 .013250$

Ibeas, J. I., and Jimenez, J. (1996). Genomic complexity and chromosomal rearrangements in wine-laboratory yeast hybrids. Curr. Genet. 30, 410-416. doi: $10.1007 / \mathrm{s} 002940050150$

Ibeas, J. I., Lozano, I., Perdigones, F., and Jimenez, J. (1996). Detection of DekkeraBrettanomyces strains in sherry by a nested PCR method. Appl. Environ. Microbiol. 62, 998-1003.

Ibeas, J. I., Lozano, I., Perdigones, F., and Jimenez, J. (1997). Dynamics of flor yeast populations during the biological ageing of Sherry wines. Am. J. Enol. Vitic. 48, 75-79.

Infante, J. J., Dombek, K. M., Rebordinos, L., Cantoral, J. M., and Young, E. T. (2003). Genome-wide amplifications caused by chromosomal rearrangements play a major role in the adaptive evolution of natural yeast. Genetics 165, 1745-1759.

Kishkovskaia, S. A., Eldarov, M. A., Dumina, M. V., Tanashchuk, T. N., Ravin, N. V., and Mardanov, A. V. (2017). Flor yeast strains from culture collection: genetic diversity and physiological and biochemical properties. Appl. Biochem. Microbiol. 53, 359-367. doi: 10.1134/S0003683817030085

Legras, J. L., Erny, C., and Charpentier, C. (2014). Population structure and comparative genome hybridization of European flor yeast reveal a unique group 
of Saccharomyces cerevisiae strains with few gene duplications in their genome. PLoS One 9:e108089. doi: 10.1371/journal.pone.0108089

Legras, J. L., and Karst, F. (2003). Optimisation of interdelta analysis for Saccharomyces cerevisiae strain characterisation. FEMS Microbiol. Lett. 221, 249-255. doi: 10.1016/S0378-1097(03)00205-2

Legras, J. L., Moreno-Garcia, J., Zara, S., Zara, G., Garcia-Martinez, T., Mauricio, J. C., et al. (2016). Flor yeast: new perspectives beyond wine aging. Front. Microbiol. 7:503. doi: 10.3389/fmicb.2016.00503

Longin, C., Guilloux-Benatier, M., and Alexandre, H. (2016). Design and performance testing of a DNA extraction assay for sensitive and reliable quantification of acetic acid bacteria directly in red wine using real time PCR. Front. Microbiol. 7:831. doi: 10.3389/fmicb.2016.00831

Martinez, P., Codon, A. C., Pérez, L., and Benitez, T. (1995). Physiological and molecular characterisation of flor yeasts: polymorphism of flor yeast populations. Yeast 11, 1399-1411. doi: 10.1002/yea.320111408

Mauricio, J. C., Valero, E., Millan, C., and Ortega, J. M. (2001). Changes in nitrogen compounds in must and wine during fermentation and biological aging by flor yeasts. J. Agric. Food Chem. 49, 3310-3315. doi: 10.1021/jf010005v

Moreno-García, J., García-Martínez, T., Moreno, J., and Mauricio, J. C. (2015). Proteins involved in flor yeast carbon metabolism under biofilm formation conditions. Food Microbiol. 46, 25-33. doi: 10.1016/j.fm.2014.07.001

Moreno-García, J., García-Martínez, T., Moreno, J., Millán, M. C., and Mauricio, J. C. (2014). A proteomic and metabolomic approach for understanding the role of the flor yeast mitochondria in the velum formation. Int. J. Food Microbiol. 172, 21-29. doi: 10.1016/j.ijfoodmicro.2013.11.030

Moreno-García, J., Mauricio, J. C., Moreno, J., and García-Martínez, T. (2017). Differential proteome analysis of a flor yeast strain under biofilm formation. Int. J. Mol. Sci. 18:E720. doi: 10.3390/ijms18040720

Naumova, E. S., Ivannikova, Y. V., and Naumov, G. I. (2005). Genetic differentiation of the sherry yeasts Saccharomyces cerevisiae. Appl. Biochem. Microbiol. 41, 578-582. doi: 10.1007/s10438-005-0105-6

Navarro-Tapia, E., Nana, R. K., Querol, A., and Perez-Torrado, R. (2016). Ethanol cellular defense induce unfolded protein response in yeast. Front. Microbiol. 7:189. doi: 10.3389/fmicb.2016.00189

Petruzzi, L., Capozzi, V., Berbegal, C., Corbo, M. R., Bevilacqua, A., and Spano, G. (2017). Microbial resources and enological significance: opportunities and benefits. Front. Microbiol. 8:995. doi: 10.3389/fmicb.2017.00995

Pozo-Bayón, A., and Moreno-Arribas, V. (2011). Sherry wines. Adv. Food Nutr. Res. 63, 17-40. doi: 10.1016/B978-0-12-384927-4.00002-6

Schuller, D., Alves, H., Dequin, S., and Casal, M. (2005). Ecological survey of Saccharomyces cerevisiae strains from vineyards in the Vinho Verde Region of Portugal. FEMS Microbiol. Ecol. 51, 167-177. doi: 10.1016/j.femsec.2004.08.003
Suarez-Lepez, J. A., and Inigo-Leal, B. (2004). Microbiologia Enological. Fundamentos de Vinificaciòn. Madrid: Ediciones Mundi-Prensa, 673-716.

Vasserot, Y., Caillet, S., and Maujean, A. (1997). Study of anthocyanin adsorption by yeast lees. Effect of some physicochemical parameters. Am. J. Enol. Vitic. 48, 433-437.

Versavaud, A., Courcoux, P., Roulland, C., Dulau, L., and Hallet, J.-N. (1995). Genetic diversity and geographical distribution of wild Saccharomyces cerevisiae strains from the wine-producing area of Charentes, France. Appl. Environ. Microbiol. 61, 3521-3529.

Vinod, P. K., Sengupta, N., Bhat, P. J., and Venkatesh, K. V. (2008). Integration of global signalling pathways, cAMP-PKA, MAPK and TOR in the regulation of FLO11. PLoS One 3:e1663. doi: 10.1371/journal.pone.0001663

Zara, G., Budroni, M., Mannazzu, I., and Zara, S. (2011). Air-liquid biofilm formation is dependent on ammonium depletion in a Saccharomyces cerevisiae flor strain. Yeast 28, 809-8014. doi: 10.1002/yea.1907

Zara, G., Goffrini, P., Lodi, T., Zara, S., and Manazzu, I. (2012). FLO11 expression and lipid biosynthesis are required for air-liquid biofilm formation in a Saccharomyces cerevisiae flor strain. FEMS Yeast Res. 12, 864-866. doi: 10.1111/ j.1567-1364.2012.00831.x

Zara, G., Zara, S., Pinna, C., Marceddu, S., and Budroni, M. (2009). FLO11 gene length and transcriptional level affect biofilm-forming ability of wild flor strains of Saccharomyces cerevisiae. Microbiology 159, 3838-3846. doi: 10.1099/mic.0. 028738-0

Zara, S., Bakalinsky, A. T., Zara, G., Pirino, G., Demontis, M. A., and Budroni, M. (2005). FLO11- based model for air-liquid interfacial biofilm formation by Saccharomyces cerevisiae. Appl. Environ. Microbiol. 71, 2934-2939. doi: 10.1128/ AEM.71.6.2934-2939.2005

Conflict of Interest Statement: The authors declare that the research was conducted in the absence of any commercial or financial relationships that could be construed as a potential conflict of interest.

The handling Editor declared a past co-authorship with one of the authors HA.

Copyright (c) 2018 David-Vaizant and Alexandre. This is an open-access article distributed under the terms of the Creative Commons Attribution License (CC BY). The use, distribution or reproduction in other forums is permitted, provided the original author(s) and the copyright owner(s) are credited and that the original publication in this journal is cited, in accordance with accepted academic practice. No use, distribution or reproduction is permitted which does not comply with these terms. 